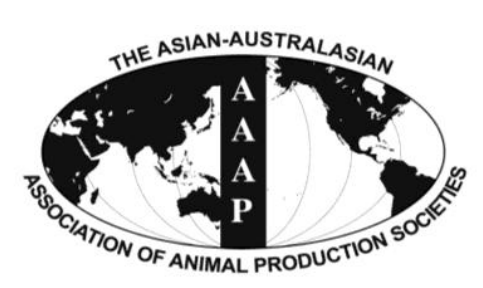

\title{
Effects of Dietary Fermented Seaweed and Seaweed Fusiforme on Growth Performance, Carcass Parameters and Immunoglobulin Concentration in Broiler Chicks
}

\author{
Y. J. Choi, S. R. Lee, and J-W. Oh' ${ }^{1, *}$ \\ Department of Animal Science and Technology, Konkuk University, Seoul 143-701, Korea
}

\begin{abstract}
This study was conducted to investigate the effects of brown seaweed (Undaria pinnatifida) by-product and seaweed fusiforme (Hizikia fusiformis) by-product supplementation on growth performance and blood profiles including serum immunoglobulin (Ig) in broilers. Fermentation of seaweeds was conducted by Bacillus subtilis and Aspergillus oryzae. In a 5-wk feeding trial, 750 one-dold broiler chicks were divided into 5 groups, and were assigned to the control diet or experimental diets including control $+0.5 \%$ brown seaweed (BS) by-product, control $+0.5 \%$ seaweed fusiforme (SF) by-product, control $+0.5 \%$ fermented brown seaweed (FBS) byproduct, and control $+0.5 \%$ fermented seaweed fusiforme (FSF) by-product. As a consequence, body weight gain (BWG) and gain:feed of seaweed by-product groups were clearly higher, when compared to those of control diet group from d 18 to 35 and the entire experimental period $(\mathrm{p}<0.05)$. In mortality rate, seaweed by-product groups were significantly lower when compared to control diet group during entire experimental period $(\mathrm{p}<0.05)$. However, Feed Intake of experimental diets group was not different from that of the control group during the entire experimental period. Whereas, Feed Intake of fermented seaweed by-product groups was lower than that of non-fermented seaweed groups ( $\mathrm{p}<0.05$ ). Total organ weights, lipids, and glutamic oxalacetic transaminase (GOT) of all treatment groups were not different from those of control group. However, glutamic pyruvate transaminase (GPT) of all treatment groups was higher than that of control group at $\mathrm{d} 17$ ( $\mathrm{p}<0.05$ ). In case of serum Igs concentration, the concentration of IgA antibody in BS, SF, FSF treatment groups was significantly higher than in control group at $\mathrm{d} 35$ ( $\mathrm{p}<0.01)$. IgA concentration in FBS supplementation groups was negligibly decreased when compared to the control group. IgM concentration in the serums of all treatment groups was significantly higher than in control group $(\mathrm{p}<0.05)$ and in fermented seaweed by-product groups were much higher than in non-fermented seaweed groups $(\mathrm{p}<0.05)$. On the other hand, IgG concentrations in all treatment groups were lower than in control group $(\mathrm{p}<0.05)$. Taken together, our results suggest that by-product dietary supplementation of BS, SF, FBS, and FSF in poultry may provide positive effects of growth performance and immune response. (Key Words: Broiler, Fermentation, Growth Performance, Immunoglobulin, Seaweed)
\end{abstract}

\section{INTRODUCTION}

In the poultry industry, feed additives and antibiotics have been used worldwide more than 50 years to enhance growth performance as well as to prevent infection of pathogens and disease. However, dietary antibiotics utilization resulted in common problems by food chain

* Corresponding Author: J-W. Oh. Tel: +82-2-2049-6271, Fax: +82-2-455-1044, E-mail: ohjw@konkuk.ac.kr

${ }^{1}$ Department of Animal Biotechnology, Konkuk University, Seoul 143-701, Korea.

Submitted Jan. 8, 2014; Revised Feb. 15, 2014; Accepted Mar. 17, 2014 from animals to man, such as development of antibiotic resistant bacteria (Phillips et al., 2004). As a consequence, antibiotic resistant and banned antibiotics have stimulated research to find effective feed additive in the world, such as herbal products, marine natural products, organic acids, microflora enhancers, probiotics, prebiotics, or combinations of these products (Engberg et al., 2000; Ayaşan and Okan, 2001, Cabuk et al., 2006; Midilli et al., 2008, Ayaşan, 2013). One of them, seaweed contains various biologically active components with different structures and functional properties (Jimenez-Escrig et al., 2011; Liu et al., 2012). In addition, the field of natural marine products have been expanded gradually (Wijesinghe

Copyright @ 2014 by Asian-Australasian Journal of Animal Sciences This is an open-access article distributed under the terms of the Creative Commons Attribution Non-Commercial License (http://creativecommons.org/licenses/by-nc/3.0/), which permits unrestricted non-commercial use, distribution, and reproduction in any medium, provided the original work is properly cited. 
and Jeon, 2012). As production of seaweeds was increased, waste of seaweed by-products was increased in the world. Therefore, the about $50 \%$ of wastes produced from brown seaweed (BS) and seaweed fusiforme (SF) has been dumped in the ocean, despite seaweeds contain edible sporophyll and root (Ahn et al., 2004). As component of seaweeds and seaweed by-products were substantially similar, seaweed by-product considered to be useful by feed additive.

Bioactive components in seaweeds include polyphenols, peptides, and polysaccharides (Zhang et al., 2007; JimenezEscrig et al., 2011). Many of these active compounds were useful functional ingredients with numerous health benefits (Yuan and Walsh, 2006; Kim and Joo, 2008). Functional polysaccharides such as fucans and alginic acid, derivatives produced by seaweeds, are known to exhibit biologically beneficial properties including anticoagulant, antiinflammatory, antiviral and antitumoral activities (Wijesinghe adn Jeon, 2012), and dietary supplementation with seaweed gives positive effects in broilers (Ventura et al., 1994). Although, however, numerous studies were reported that seaweeds have potential as effective additives, some of seaweed components could interfere with bioavailability of diet (Michel et al., 1996; MacArtain et al., 2007), and availability could be decreased in animals (Katayama et al., 2011). In this regard, research for SF byproducts and increased availability by them has not been performed by fermentation.

Therefore, this study was conducted to determine bioavailability improvement of feed diet by seaweed fermentation, and to evaluate growth performance and blood profiles in broilers fed with by-product of BS and SF.

\section{MATERIALS AND METHODS}

\section{Microbes and fermentation measurement}

By-products of BS (Undaria pinnatifida) and SF (Hizikia fusiformis) were collected from Wando island (South Korea). Fermentation was performed using five different types of microbes: Bacillus subtilis, Pediococcus acidilacti, Pediococcus pentosaceus, Saccharomyces cerevisiae, and Aspergillus oryzae (Table 1). Microbes were selected for experiment using animal on the basis of seaweed decomposition, pathogenicity and exchange ratio of the sugar contents. The capability of seaweed decomposition was calculated by ratio of reduced sugar. End-point criteria of fermentation were determined by total sugar, reduced sugar, and $\mathrm{pH}$. Fermentation condition was handled according to the optimum growth conditions based on American type culture collection guideline (Sneath et al., 1986). Light microscope (Olympus, Japan), and scanning electron microscope (Phillips, Andover, MA, USA) were employed to compare on seaweed by-products after
Table 1. Microbial strains used for the fermentation of byproducts of brown seaweed and seaweed fusiforme

\begin{tabular}{lll}
\hline Strains & Classification & \multicolumn{1}{c}{ Origin } \\
\hline Bacillus subtilis & Bacteria & ATCC $^{1} 21228$ \\
Pediococcus acidilactis & Bacteria & Kimchi $^{2}$ \\
Pediococcus pentosaceus & Bacteria & Yogurt $^{3}$ \\
Saccharomyces cerevisiae & Yeast & ATCC 24858 \\
Aspergillus oryzae & Fungi & ATCC 14895 \\
\hline
\end{tabular}

${ }^{1}$ ATCC, American type culture collection.

${ }^{2}$ Isolation and identification from Kimchi.

${ }^{3}$ Isolation and identification from Yogurt.

fermentation.

\section{Animal and experimental design}

A total of 750 of one-d-old Ross male $(44.17 \pm 0.05)$ chicks were randomly allocated to five treatments replicated five times in such a way that each had 30 birds. The experiment was conducted as a completely randomized design with a control and $2 \times 2$ factorial arrangement. Birds were randomly distributed in each pen $(\mathrm{W} \times \mathrm{H} \times \mathrm{D}$ : 180 $\mathrm{cm} \times 180 \mathrm{~cm} \times 200 \mathrm{~cm}$ ) according to similar body weight (BW). Experimental diets were formulated according to NRC guideline (1994, Table 4). Treatments included control (basal diet), control+0.5\% BS by-product, control+0.5\% SF by-product, control+0.5\% fermented brown seaweed (FBS) by-product, and control $+0.5 \%$ fermented seaweed fusiforme (FSF) by-product. The experimental diets were fed to chicks for $5 \mathrm{wk}$ with plan of both starter diet (d 0 to 17) and subsequently grower diet (d 18 to 35 ). Total chick's weight of each pen was established to be equal, and feeder was separately allocated at each pen. Ten water nipples were also allocated to be equivalent space at each pen. Feed and water were provided ad-libitum. Ambient temperature was maintained $33^{\circ} \mathrm{C}$ on d 0 and was maintained $29^{\circ} \mathrm{C}$ on the rest weeks. Humidity was maintained to be higher than $60 \%$.

\section{Growth performance and organ weight measurement}

Body weight and feed intake were recorded on d $0, \mathrm{~d} 17$, and $d$ 35. Feed intake was determined by measuring feed residue on $\mathrm{d} 0, \mathrm{~d} 17$, and $\mathrm{d} 35$ bases from the start of the experiment. The ratio of gain:feed (G:F) was calculated as the body weight gain (BWG)/feed intake. Mortalities (\%) were recorded daily, and data of feed intake were corrected for BW of dead birds. Mortality (\%) was calculated as follows,

\section{Number of dead birds in group \\ Initial number of birds in the group}

Spleen, bursa of fabricius, abdominal fat, and breast muscle weight were measured with each sample obtained from 2 chicks per each pen at d 35. The organ weight was 
calculated as $\mathrm{g} / 100 \mathrm{~g} \mathrm{BW}$.

\section{Blood profile and immunoglobulins (Ig) analysis}

On d 17 and d 35, 2 chicks were randomly selected from each pen, and blood samples were collected from brachial vein using $5 \mathrm{~mL}$ syringe (BD, Franklin Lakes, NJ, USA), and then were immediately centrifuged at $1,500 \times \mathrm{g}$ for $15 \mathrm{~min}$ at $4^{\circ} \mathrm{C}$. Each serum after centrifugation was stored at $-20^{\circ} \mathrm{C}$ until use. Lipid layers of blood were analyzed for content comparison of triglyceride, totalcholesterol, high-density lipoprotein cholesterol, glutamic oxaloacetic transaminase (GOT), and glutamic pyruvic transaminase (GPT) using automated blood analyzer (Sysmex, Seoul, Korea). Immunoglobulins (Ig)A, IgG, and IgM antibodies were detected using enzyme-linked immunosorbent assay kits (BETHYL, Montgomery, TX, USA). Absorbance for detection was determined at $470 \mathrm{~nm}$ using a microplate reader (Bio-Tek, Winooski, VT, USA).

\section{Statistical analysis}

Data were analyzed using the MIXED procedure of SAS (SAS Inst. 2011) as a completely randomized design. Model was

$$
\mathrm{Y}=\mu+\mathrm{T}_{\mathrm{i}}+\mathrm{E}_{\mathrm{ij}}
$$

Where, $\mu$ is average value, $T_{i}$ is treatment value, $E_{i j}$ is the error value. Fixed effect was supplement effect; random effect was not considered in procedure. Orthogonal contrasts were used to study seaweed effect and fermentation effect using CONTRAST option. Contrasts included control versus by-product supplement (contrast 1), BS by-product versus SF by-product (contrast 2); nonfermented by-product vs. fermented by-product (contrast 3); interaction between seaweed source and fermentation (contrast 4). Significant differences among the treatments were determined at $\mathrm{p}<0.05$ whereas a trend was expressed when $p<0.10$. All means presented are least square means.

\section{RESULT AND DISCUSSION}

\section{Microbes and fermentation}

Five microbes were compared on the basis of commercial potential, pathogenicity, as well as exchange ratio of the reduced sugar contents during fermentation periods (Table 2). Finally, two different types microbes, Bacillus subtilis and Aspergillus oryzae, were selected for next experiment. Comparison of the chemical compositions in between BS and FBS showed considerable increase of carbohydrates contents from $29.84 \%$ to $45.13 \%$, and comparison in between SF and FSF also showed considerable increase from $40.73 \%$ to $49.20 \%$ (Table 3).
Table 2. Effect of various microbial strains on total and reduced sugar contents in the by-products of brown seaweed and seaweed fusiforme

\begin{tabular}{lccccc}
\hline \multirow{2}{*}{ Strains } & \multicolumn{3}{c}{ Sugar contents $(\mu \mathrm{g} / \mathrm{mL})$} \\
\cline { 2 - 3 } \cline { 2 - 3 } \cline { 6 - 7 } & \multicolumn{2}{c}{ FBS } & & \multicolumn{2}{c}{ FSF } \\
\cline { 2 - 3 } \cline { 6 - 7 } Bacillus subtilis & Total & Reduced & & Total & Reduced \\
Pediococcus acidilactis & 224.1 & 6.53 & & 206.7 & 21.5 \\
Pediococcus pentosaceus & 479.6 & 7.04 & & 1048.0 & 20.0 \\
Saccharomyces cerevisiae & 92.6 & 2.64 & & 908.2 & 23.2 \\
Aspergillus oryzae & 144.2 & 0.80 & & 771.4 & 28.5 \\
\hline
\end{tabular}

FBS, fermented brown seaweed by-product; FSF, fermented seaweed fusiforme by-product.

The other chemicals were shown minimal variations. As well, gradual decrease of $\mathrm{pH}$ by microbes during fermentation was observed in both cases as time goes on (Figures 1 and 2). On the contrary, increase of total sugars and reduced sugars by microbes was also observed (Figures 1 and 2). Microscopic results of fermented seaweeds byproduct indicate that fermentation may affect each byproduct to morphological changes to increase carbohydrate digestibility in broilers (Figure 3).

\section{Growth performance}

Body weight was not different between all treatment groups as well as the control group when measured at $\mathrm{d} 0, \mathrm{~d}$ 17, and d 35 (Table 5). The BWG was also not different between all treatment groups and the control group at the beginning (d 0). However, body weight gain of BS, SF, FBS, and FSF was clearly higher than that of the control group both in the growth period and in the entire experimental

Table 3. The chemical composition in the by-products of brown seaweed, seaweed fusiforme, fermented brown seaweed and fermented seaweed fusiforme

\begin{tabular}{|c|c|c|c|c|}
\hline \multirow{2}{*}{$\begin{array}{l}\text { Chemical } \\
\text { composition } \\
(\% \mathrm{DM})\end{array}$} & \multicolumn{4}{|c|}{ Treatment } \\
\hline & BS & FBS & SF & FSF \\
\hline $\mathrm{CP}$ & 17.38 & 18.41 & 18.41 & 20.04 \\
\hline Ether extract & 0.57 & 0.85 & 0.11 & 0.12 \\
\hline Carbohydrate $^{2}$ & 29.84 & 45.13 & 40.73 & 49.20 \\
\hline Crude ash & 28.42 & 20.22 & 16.63 & 15.04 \\
\hline $\mathrm{Ca}$ & 0.93 & 1.27 & 0.87 & 0.93 \\
\hline $\mathrm{P}$ & 0.28 & 0.37 & 0.11 & 0.12 \\
\hline $\mathrm{Fe}$ & 0.59 & 0.98 & 1.43 & 0.16 \\
\hline $\mathrm{Zn}$ & 0.24 & 0.31 & 0.15 & 0.17 \\
\hline $\mathrm{Mg}$ & 0.69 & 0.01 & 0.01 & 0.01 \\
\hline $\mathrm{K}$ & 0.63 & 0.41 & 0.32 & 0.36 \\
\hline $\mathrm{Na}$ & 0.72 & 0.55 & 0.16 & 0.22 \\
\hline
\end{tabular}

DM, dry matter; BS, brown seaweed by-product; FBS, fermented brown seaweed by-product; SF, seaweed fusiforme by-product; FSF, fermented seaweed fusiforme by-product; $\mathrm{CP}$, crude protein.

${ }^{2}$ Calculated value $=[$ Sample $100 \mathrm{~g}-($ moisture $+\mathrm{CP}+$ ether extract+crude ash)]/100 $\mathrm{g} \times 100$. 

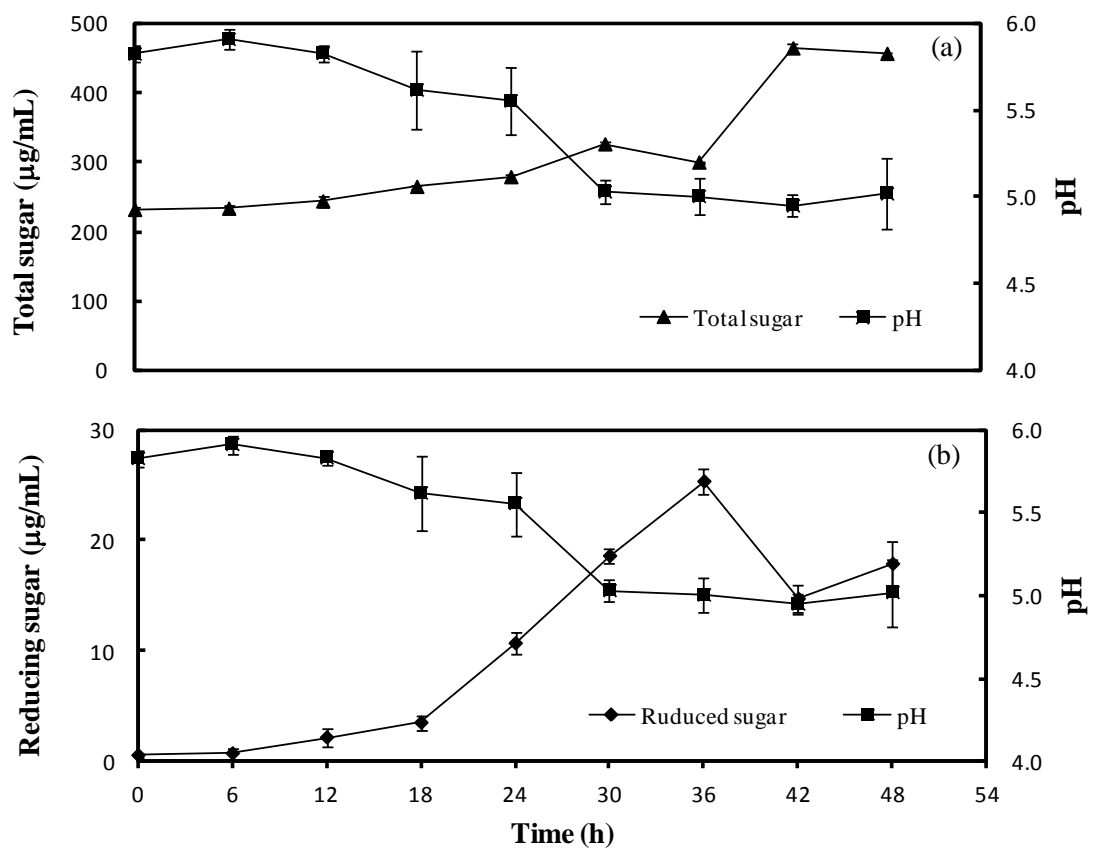

Figure 1. The variations of $\mathrm{pH}$, total sugar and reduced sugar contents in the brown seaweed by-product. Moisture content in the brown seaweed by-product was adjusted to $70 \%$, and $10^{8} \mathrm{cfu} / \mathrm{g}$ of $\mathrm{B}$. subtilis were inoculated and incubated further for $48 \mathrm{~h}$. (a) comparison between $\mathrm{pH}$ and total sugar; (b) comparison between $\mathrm{pH}$ and reduced sugar; error bar means SE value.

periods $(\mathrm{p}<0.05)$. Feed intake in all treatment groups was not different from that of the control group in the entire experimental period, except for contrast 3 during d 0 to 17 . In feed intake contrast 3 at $\mathrm{d} 0$ to 17 , it in non-fermented groups was higher than in fermented groups $(p<0.05)$. Gain:feed was improved both at the growth period and in the entire experimental periods when compared with the control group $(\mathrm{p}<0.05)$. Mortality $(\%)$ of all treatments was clearly lower when compared to the control group $(\mathrm{p}<0.05)$.

It was previously reported that dietary supplementation of red algae affects feed efficiency in broiler (El-Deek adn Brikaa, 2009), and dietary supplementation of microbes
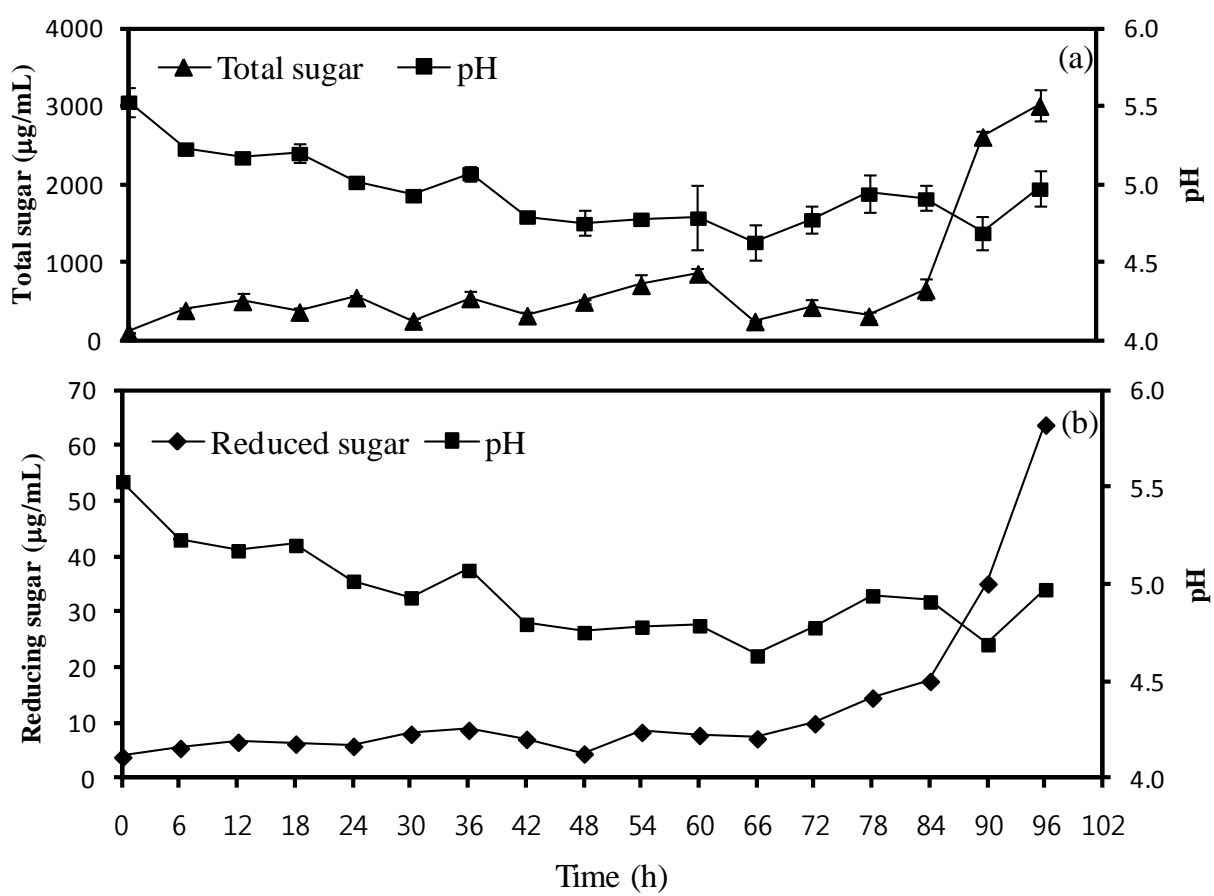

Figure 2. The variations of $\mathrm{pH}$, total sugar and reduced sugar contents in the seaweed fusitorme by-product. Moisture content in the seaweed fusiforme by-product was adjusted to $55 \%$, and $10^{5} \mathrm{cfu} / \mathrm{g}$ of $A$. oryzae were inoculated and incubated further for $96 \mathrm{~h}$. (a), comparison between $\mathrm{pH}$ and total sugar; (b), comparison between $\mathrm{pH}$ and reduced sugar; error bar means $\mathrm{SE}$ value. 


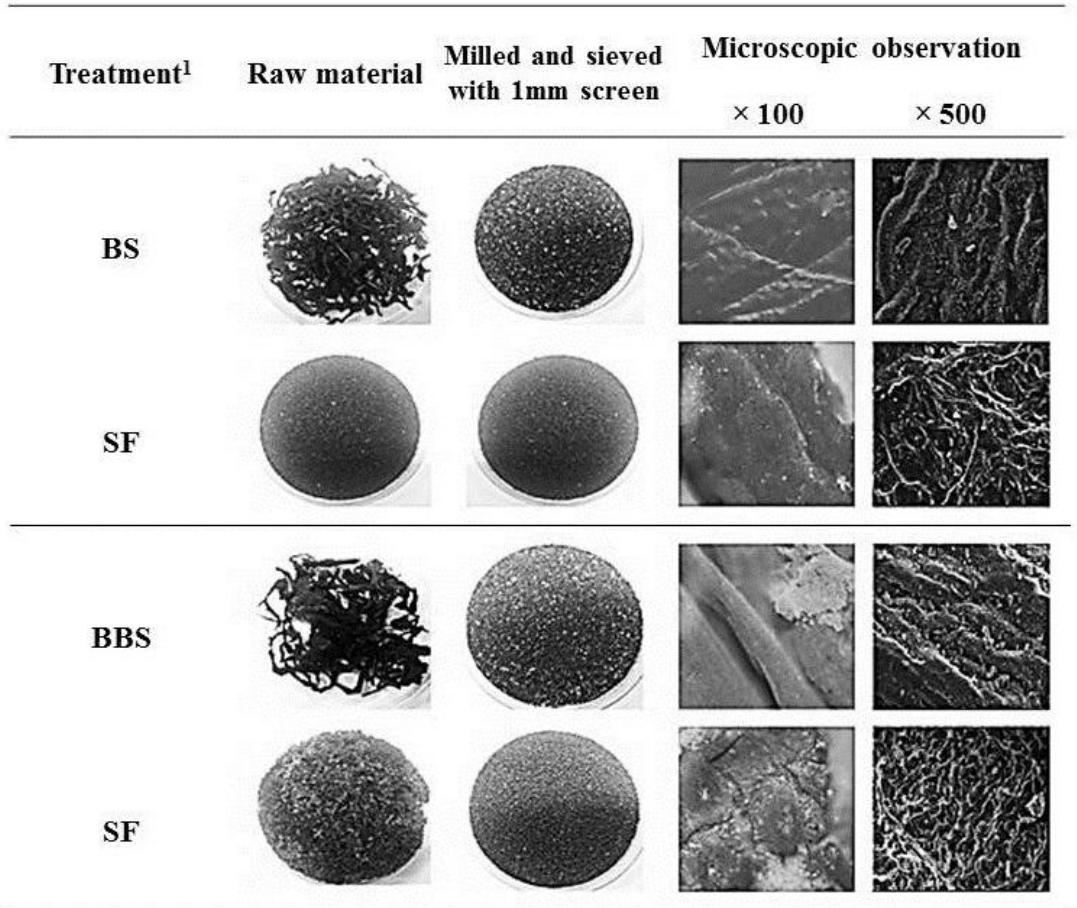

Figure 3. Electron microscopic photographs of the fermented or non-fermented by-products, obtained in raw or milled brown seaweed and seaweed fusiforme. ${ }^{1}$ BS, brown seaweed by-product; SF, seaweed fusiforme by-product; FBS, fermented brown seaweed byproduct; FSF, fermented seaweed fusiforme by-product.

also affect feed efficiency (Shimada et al., 2004). In this study, we showed that supplementation of BS and SF has positive effect, increasing BWG, G:F, and mortality $(p<0.05)$. Although BW of all treatment groups was not different from that of the control group, magnitude of BWG improvement was $2 \%$, on average. As well, magnitude of BWG improvement was over $4 \%$, on average because BS and SF addition may have a positive effect in broiler.

Table 4. Formula and calculated nutritional values of the basal starter and finisher diets

\begin{tabular}{|c|c|c|c|c|c|}
\hline Item & $\begin{array}{c}\text { Starter } \\
\text { (d } 0 \text { to } 17)\end{array}$ & $\begin{array}{l}\text { Finisher } \\
\text { (d } 18 \text { to } 35 \text { ) }\end{array}$ & & $\begin{array}{c}\text { Starter } \\
\text { (d } 0 \text { to } 17 \text { ) }\end{array}$ & $\begin{array}{l}\text { Finisher } \\
\text { (d } 18 \text { to } 35 \text { ) }\end{array}$ \\
\hline Ingredient (\%, fed basis) & & & \multicolumn{3}{|c|}{ Nutrient (\%, as fed basis, analysis results) } \\
\hline Yellow corn & 56.40 & 60.00 & $\mathrm{DM}$ & 89.23 & 89.57 \\
\hline Soybean meal (CP, $46.17 \%)$ & 25.80 & 20.40 & $\mathrm{CP}$ & 21.00 & 20.00 \\
\hline Corn gluten meal (CP, $62.22 \%)$ & 3.00 & 5.00 & Ether extract & 7.75 & 7.75 \\
\hline Full fat soybean (CP, 36.5\%) & 5.00 & 5.00 & Crude fiber & 2.96 & 2.96 \\
\hline Finish meal & 2.00 & 2.00 & Crude ash & 5.67 & 5.67 \\
\hline Tallow & 4.30 & 4.20 & $\mathrm{Ca}$ & 1.00 & 1.00 \\
\hline Dicalcium phosphate & 1.74 & 1.62 & $\mathrm{P}$ & 0.71 & 0.71 \\
\hline Limestone & 0.96 & 1.07 & Lysine & 1.24 & 1.24 \\
\hline Salt & 0.22 & 0.22 & Methionine & 0.58 & 0.58 \\
\hline L-lysine $\cdot \mathrm{HCl}(78 \%)$ & 0.18 & 0.16 & $\operatorname{TMEn}^{2}(\mathrm{kcal} / \mathrm{kg})$ & 3,150 & 3,200 \\
\hline DL-methionine (98\%) & 0.20 & 0.10 & & & \\
\hline L-threonine (99\%) & 0.05 & 0.08 & & & \\
\hline Vitamin and trace mineral premix ${ }^{1}$ & 0.15 & 0.15 & & & \\
\hline Total & 100.00 & 100.00 & & & \\
\hline
\end{tabular}

CP, crude protein; DM, dry matter; TMEn, nitrogen-corrected true metabolizable energy.

${ }^{1}$ Vitamin and trace mineral mixture powder provides the following nutrients per kg of diet; vitamin A, 12,000 IU; vitamin $\mathrm{D}_{3}, 2,500 \mathrm{IU}$; vitamin E, $20 \mathrm{IU}$; vitamin $\mathrm{K}_{3}, 1.8 \mathrm{mg}$; vitamin $\mathrm{B}_{1}, 2,000 \mathrm{mg}$; vitamin $\mathrm{B}_{2}, 6,000 \mathrm{mg}$; vitamin $\mathrm{B}_{6}, 3.0 \mathrm{mg}$; vitamin $\mathrm{B}_{12}, 20 \mu \mathrm{g}$; niacin, $25 \mathrm{mg}$; pantothenic acid, $10 \mathrm{mg}$; folic

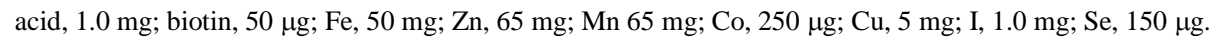

${ }^{2}$ Calculated value (NRC, 1994). 
Table 5. Effects of dietary supplementation of non-fermented or fermented brown seaweed and seaweed fusiforme by-products on growth performance in broiler chickens ${ }^{1}$

\begin{tabular}{|c|c|c|c|c|c|c|c|c|c|c|c|}
\hline \multirow{2}{*}{ Items } & \multirow{2}{*}{$\begin{array}{l}\text { Period } \\
\text { (d) }\end{array}$} & \multicolumn{5}{|c|}{ Treatment $^{2}$} & \multirow{2}{*}{ SEM } & \multicolumn{4}{|c|}{ Contrast $^{3}$} \\
\hline & & $\mathrm{CON}$ & BS & FBS & $\mathrm{SF}$ & FSF & & 1 & 2 & 3 & 4 \\
\hline \multirow{3}{*}{$\begin{array}{l}\text { BW } \\
\text { (g/bird) }\end{array}$} & 0 & 44.5 & 44.5 & 44.4 & 44.5 & 44.4 & 0.39 & 0.624 & 1.000 & 1.000 & 1.000 \\
\hline & 17 & 498 & 507 & 480 & 492 & 481 & 13.1 & 0.534 & 0.533 & 0.100 & 0.474 \\
\hline & 35 & 1,795 & 1,872 & 1,840 & 1,835 & 1,807 & 41.1 & 0.185 & 0.226 & 0.293 & 0.938 \\
\hline \multirow{3}{*}{$\begin{array}{l}\text { BWG } \\
\text { (g/bird) }\end{array}$} & 0 to 17 & 454 & 463 & 436 & 448 & 437 & 13.1 & 0.526 & 0.534 & 0.103 & 0.474 \\
\hline & 18 to 35 & 1,222 & 1,321 & 1,324 & 1,287 & 1,278 & 30.8 & 0.004 & 0.088 & 0.875 & 0.785 \\
\hline & 0 to 35 & 1,626 & 1,750 & 1,730 & 1,693 & 1,678 & 41.1 & 0.015 & 0.076 & 0.541 & 0.928 \\
\hline \multirow{3}{*}{$\begin{array}{l}\text { Feed intake } \\
\text { (g/bird) }\end{array}$} & 0 to 17 & 1,014 & 1,122 & 997 & 1,094 & 996 & 19.9 & 0.105 & 0.473 & $<0.001$ & 0.495 \\
\hline & 18 to 35 & 2,434 & 2,364 & 2,313 & 2,312 & 2,368 & 38.0 & 0.147 & 0.977 & 0.958 & 0.356 \\
\hline & 0 to 35 & 3,356 & 3,437 & 3,265 & 3,345 & 3,304 & 61.9 & 0.795 & 0.677 & 0.101 & 0.302 \\
\hline \multirow[t]{3}{*}{ G:F } & 0 to 17 & 0.44 & 0.42 & 0.44 & 0.43 & 0.44 & 0.014 & 0.319 & 0.916 & 0.159 & 0.857 \\
\hline & 18 to 35 & 0.50 & 0.56 & 0.57 & 0.56 & 0.54 & 0.014 & 0.003 & 0.233 & 0.854 & 0.317 \\
\hline & 0 to 35 & 0.48 & 0.51 & 0.53 & 0.51 & 0.51 & 0.012 & 0.036 & 0.286 & 0.367 & 0.440 \\
\hline Mortality (\%) & 0 to 35 & 6.00 & 1.33 & 0.67 & 2.00 & 0.67 & 0.329 & $<0.001$ & 0.764 & 0.372 & 0.764 \\
\hline
\end{tabular}

BS, brown seaweed by-product; FBS, fermented brown seaweed by-product; SF, seaweed fusiforme by-product; FSF, fermented seaweed fusiforme byproduct; SEM, standard error of the mean; BW, body weight; BWG, body weight gain; G:F, ratio of gain:feed.

${ }^{1}$ Each least square means represents 5 pens of 30 birds per pen.

${ }^{2} \mathrm{CON}=$ Basal diet; $\mathrm{BS}=$ Basal diet+0.5\% BS by-product; FBS $=$ Basal diet+0.5\% FBS by-product; $\mathrm{SF}=$ Basal diet+0.5\% SF by-product; $\mathrm{FSF}=\mathrm{Basal}$ diet $+0.5 \%$ FSF by-product.

${ }^{3} 1$ = Control vs by-product supplement; 2 = BS by-product vs SF by-product; $3=$ Non-fermented by-product vs fermented by-product; $4=$ Interaction between seaweed source and fermentation.

Although, in case of feed intake for seaweed source versus fermentation, our result showed that fermentation decreases feed intake and palatability during d 0 to 17 (El-Deek and Brikaa, 2009), and feed intake is not different from that of the control group after $d 18$. This result suggests that chicks are adapted for experimental feeding. On the other hands, Cabuk et al. (2006) reported that seaweeds does not give directly affects in mortalities. Thus, our result regarding mortality (\%), may be affected through the microbes fermentation.

The organ weights of all treatment groups when sacrificed at d 35 were not different from that of the control group (Table 6). It was previously reported that organ weight is affected by dietary probiotics supplementation (Awad et al., 2009). However, Lokaewmanee et al. (2012) reported that weight of organs has no difference between in group of dietary fermented plant products supplementation and in control group, except for total visceral weights on poultry. In this study, likewise, weight of organs had no difference between in the control and in all treatment groups. This result indicates that amounts of fed microbes may be lower than probiotics.

\section{Blood profiles}

Blood profiles in all treatment groups were not different from that in the control group, but GPT of all treatment groups was higher than in control group from $\mathrm{d} 0$ to $\mathrm{d} 17$ $(p<0.05) \quad($ Table 7). Likewise, it was reported that supplementation of FBS to broilers does not affect at blood composition (Lokaewmanee et al., 2012). As well, fed

Table 6. Effects of dietary supplementation of non-fermented or fermented brown seaweed and seaweed fusiforme by-products on relative weights of organs in broiler chickens ${ }^{1}$

\begin{tabular}{|c|c|c|c|c|c|c|c|c|c|c|}
\hline \multirow{2}{*}{ Items } & \multicolumn{5}{|c|}{ Treatment $^{2}(\mathrm{~g} / 100 \mathrm{~g} \mathrm{BW})$} & \multirow{2}{*}{ SEM } & \multicolumn{4}{|c|}{ Contrast $^{3}$} \\
\hline & $\mathrm{CON}$ & $\mathrm{BS}$ & FBS & SF & FSF & & 1 & 2 & 3 & 4 \\
\hline Spleen & 0.103 & 0.108 & 0.117 & 0.107 & 0.103 & 0.169 & 0.539 & 0.390 & 0.873 & 0.426 \\
\hline Bursa of fabricius & 0.187 & 0.208 & 0.190 & 0.169 & 0.167 & 0.285 & 0.980 & 0.070 & 0.350 & 0.593 \\
\hline Abdominal fat & 1.702 & 1.702 & 1.681 & 1.448 & 1.778 & 1.999 & 0.937 & 0.660 & 0.245 & 0.116 \\
\hline Breast muscle & 8.340 & 7.799 & 8.356 & 7.767 & 8.317 & 4.590 & 0.768 & 0.639 & 0.100 & 0.978 \\
\hline
\end{tabular}

BW, body weight; BS, brown seaweed by-product; FBS, fermented brown seaweed by-product; SF, seaweed fusiforme by-product; FSF, fermented seaweed fusiforme by-product; SEM, standard error of the mean.

${ }^{1}$ Each least square means represents 5 pens of 2 birds per pen.

${ }^{2} \mathrm{CON}=$ Basal diet; $\mathrm{BS}=$ Basal diet+0.5\% BS by-product; FBS = Basal diet+0.5\% FBS by-product; SF = Basal diet $+0.5 \%$ SF by-product; FSF $=$ Basal diet+0.5\% FSF by-product.

${ }^{3} 1$ = Control vs by-product supplement; 2 = BS by-product vs SF by-product; $3=$ Non-fermented by-product vs fermented by-product; $4=$ Interaction between seaweed source and fermentation. 
Table 7. Effects of dietary supplementation of non-fermented or fermented brown seaweed and seaweed fusiforme by-products on lipid of serum in broiler chickens ${ }^{1}$

\begin{tabular}{|c|c|c|c|c|c|c|c|c|c|c|c|}
\hline \multirow{2}{*}{ Items } & \multirow{2}{*}{$\begin{array}{l}\text { Period } \\
\text { (d) }\end{array}$} & \multicolumn{5}{|c|}{ Treatment $^{2}$} & \multirow{2}{*}{ SEM } & \multicolumn{4}{|c|}{ Contrast $^{3}$} \\
\hline & & $\mathrm{CON}$ & BS & FBS & SF & FSF & & 1 & 2 & 3 & 4 \\
\hline \multirow{2}{*}{$\begin{array}{l}\text { Triglyceride } \\
(\mathrm{mg} / \mathrm{dL})\end{array}$} & 17 & 118.6 & 120.4 & 122.8 & 110.9 & 118.4 & 11.15 & 0.943 & 0.513 & 0.641 & 0.810 \\
\hline & 35 & 53.6 & 54.8 & 53.9 & 54.9 & 55.3 & 3.46 & 0.760 & 0.820 & 0.940 & 0.844 \\
\hline \multirow{2}{*}{$\begin{array}{l}\text { Total-cholesterol } \\
(\mathrm{mg} / \mathrm{dL})\end{array}$} & 17 & 145.0 & 153.0 & 154.2 & 160.4 & 152.7 & 7.11 & 0.286 & 0.663 & 0.631 & 0.512 \\
\hline & 35 & 154.2 & 138.8 & 147.6 & 146.8 & 148.3 & 6.37 & 0.126 & 0.355 & 0.375 & 0.547 \\
\hline \multirow{2}{*}{$\begin{array}{l}\text { HDL-cholesterol } \\
(\mathrm{mg} / \mathrm{dL})\end{array}$} & 17 & 106.7 & 111.7 & 113.4 & 122.0 & 115.0 & 5.64 & 0.166 & 0.197 & 0.573 & 0.360 \\
\hline & 35 & 111.3 & 96.9 & 104.4 & 106.3 & 96.9 & 4.53 & 0.133 & 0.903 & 0.843 & 0.157 \\
\hline \multirow[t]{2}{*}{ GOT (IU/L) } & 17 & 181.0 & 182.8 & 181.2 & 187.1 & 174.5 & 5.81 & 0.958 & 0.828 & 0.203 & 0.322 \\
\hline & 35 & 235.4 & 241.3 & 232.4 & 217.8 & 236.0 & 9.47 & 0.708 & 0.241 & 0.581 & 0.113 \\
\hline \multirow[t]{2}{*}{ GPT (IU/L) } & 17 & 0.50 & 0.88 & 1.21 & 1.60 & 1.30 & 0.28 & 0.038 & 0.118 & 1.000 & 0.237 \\
\hline & 35 & 2.42 & 2.01 & 2.19 & 2.33 & 2.04 & 0.28 & 0.365 & 0.853 & 0.852 & 0.358 \\
\hline
\end{tabular}

BS, brown seaweed by-product; FBS, fermented brown seaweed by-product; SF, seaweed fusiforme by-product; FSF, fermented seaweed fusiforme byproduct; SEM, standard error of the mean; GOT, glutamic oxaloacetic transaminase; GPT, glutamic pyruvic transaminase.

${ }^{1}$ Each least square means represents 5 pens of 2 birds per pen.

${ }^{2} \mathrm{CON}=$ Basal diet; $\mathrm{BS}=$ Basal diet $+0.5 \%$ BS by-product; FBS $=$ Basal diet $+0.5 \%$ FBS by-product; $\mathrm{SF}=$ Basal diet $+0.5 \%$ SF by-product; FSF $=$ Basal diet $+0.5 \%$ FSF by-product.

${ }^{3} 1$ = Control vs by-product supplement; $2=$ BS by-product vs SF by-product; $3=$ Non-fermented by-product vs fermented by-product; $4=$ Interaction between seaweed source and fermentation.

seaweed extract was reported to decrease oxidative stress such as GOT, GPT concentration on animals (Kang et al., 2008). However, our result shows that GPT in all treatment groups was higher than in the control at $d 17(\mathrm{p}<0.05)$. These results may be due to effect of detoxification by microbes in the liver in feed additives on broiler (ElHusseiny et al., 2008).

\section{Immunoglobulin concentration}

Immunoglobulin concentration in the serum was measured in broiler fed for $35 \mathrm{~d}$ (Table 8). As a result, the concentration of IgA antibody in the supplementation group were considerably higher than in the control group, except FBS supplemented group $(\mathrm{p}<0.01)$. As well, IgA antibody concentration was increased by fermentation both in $\mathrm{SF}$ and FSF group when compared to control group $(\mathrm{p}<0.01)$. Interestingly, FSF supplementation in broiler showed significant increase of IgA antibody concentration when compared to SF group, meaning positive effects of fermentation with seaweed fusiform. In case of $\mathrm{IgG}$ antibody, its concentration in the supplemented groups were significantly lower than in the control group $(p<0.01)$. As well, it was observed that IgG antibody concentration was decreased in the both of BS and SF non-fermented group $(\mathrm{p}<0.01)$. Furthermore, IgG antibody reduction rate of BS group was significantly higher than in SF group $(p<0.01)$, suggesting importance of seaweed source. In case of IgM antibody, all treatment groups were significantly higher than in the control group $(\mathrm{p}<0.05)$. IgM concentration was the most highly increased in FBS and FSF group, compared to other groups including control group $(\mathrm{p}<0.05)$. In addition, IgM concentration in the fermentation groups were higher than in the non-fermentation groups $(\mathrm{p}<0.01)$. It means that supplementation of fermented seaweeds in the diet may increase IgM antibody concentration in broiler $(\mathrm{p}<0.01)$.

Allen and Pond (2002) recently reported that seaweed extract improved activation of immune system in poultry and mammals. In accord with their results, the increased

Table 8. Effects of dietary supplementation of non-fermented or fermented brown seaweed and seaweed fusiforme by-products on immunoglobulin concentration in the serum of broiler chickens ${ }^{1}$

\begin{tabular}{|c|c|c|c|c|c|c|c|c|c|c|}
\hline \multirow{2}{*}{ Items } & \multicolumn{5}{|c|}{ Treatment $^{2}(35 \mathrm{~d})$} & \multirow{2}{*}{ SEM } & \multicolumn{4}{|c|}{ Contrast $^{3}$} \\
\hline & $\mathrm{CON}$ & $\mathrm{BS}$ & FBS & SF & FSF & & 1 & 2 & 3 & 4 \\
\hline$\overline{\mathrm{IgA}(\mathrm{mg} / \mathrm{dL})}$ & 203 & 228 & 199 & 226 & 241 & 4.9 & 0.003 & $<0.001$ & 0.130 & $<0.001$ \\
\hline $\operatorname{IgG}(\mathrm{mg} / \mathrm{dL})$ & 679 & 564 & 372 & 652 & 609 & 14.7 & $<0.001$ & $<0.001$ & $<0.001$ & $<0.001$ \\
\hline $\operatorname{IgM}(\mathrm{mg} / \mathrm{dL})$ & 176 & 188 & 214 & 182 & 218 & 8.0 & 0.030 & 0.839 & $<0.001$ & 0.451 \\
\hline
\end{tabular}

BS, brown seaweed by-product; FBS, fermented brown seaweed by-product; SF, seaweed fusiforme by-product; FSF, fermented seaweed fusiforme byproduct; SEM, standard error of the mean; Ig, immunoglobulin.

${ }^{1}$ Each least square means represents 5 pens of 2 birds per pen.

${ }^{2} \mathrm{CON}=$ Basal diet; $\mathrm{BS}=$ Basal diet+0.5\% BS by-product; FBS = Basal diet+0.5\% FBS by-product; SF = Basal diet+0.5\% SF by-product; FSF = Basal diet+0.5\% FSF by-product.

${ }^{3} 1$ = Control vs by-product supplement; 2 = BS by-product vs SF by-product; $3=$ Non-fermented by-product vs fermented by-product; $4=$ Interaction between seaweed source and fermentation. 
serum concentration of $\operatorname{Ig}$ A antibody in BS, SF, and FSF, and the increase of IgM antibody in BS, SF, FBS, and FSF groups suggest that the immune system for antibody production in broiler may be improved by supplementation of fermented seaweeds with microbes in diets.

Therefore, although fermentation does not affect on growth performance and blood profiles in broiler, BS and SF may be considered as effective feed additives on poultry. In addition, the modulation of $\operatorname{IgA}, \operatorname{IgM}$, and $\operatorname{IgG}$ antibody by supplementation of fermented seaweed in broiler may be connected to reinforcement of physical health by activation of humoral immune response in that antibodies are involved in poultry.

\section{CONCLUSION}

Brown seaweed and SF have a lot of biological effects and a large amount of by-product was produced annually in the world. Although seaweeds have low digestibility and utilization in the animals, fermentation technique may assist the increase of reutilization and digestibility. In addition, fermentation may improve growth performance and immune response. Although, in this study, fermentation effect was minimal, supplementation of BS and SF had a great effect on growth performance. In conclusion, our results suggest that dietary supplementation of by-product of BS, SF, FBS, and FSF in poultry may improve growth performance and immune response.

\section{REFERENCES}

Ahn, S. J., Y. S. Kim, and K. P. Park. 2004. Storage of wastebrown seaweed and degradation of alginate using microorganism. J. Environ. Sci. 13:313-318.

Allen, V. G. and K. R. Pond. 2002. Seaweed Supplement Diet for Enhancing Immune Response in Mammals and Poultry. Texas Tech University, Lubbock, TX, USA.

Ayaşan, T. and F. Okan. 2001. The effect of a diet with different probiotic (protexin) levels on the fattening performance and carcass characteristics of Japanese quails. Proceedings of XVth European Symposium on the Quality of Poultry Meat. September 9-12, 2011; Kuşadas1, Turkey. pp. 169-174.

Ayaşan, 2013. Effects of dietary inclusion of protexin (probiotic) on hatchability of Japanese quails. Indian J. Anim. Sci. 83:7881.

Awad, W., K. Ghareeb, S. Abdel-Raheem, and J. Böhm. 2009. Effects of dietary inclusion of probiotic and synbiotic on growth performance, organ weights, and intestinal histomorphology of broiler chickens. Poult. Sci. 88:49-56.

Cabuk, M., M. Bozkurt, A. Alcicek, Y. Akbas, and K. Kücükyilmaz. 2006. Effect of a herbal essential oil mixture on growth and internal organ weight of broilers from young and old breeder flocks. S. Afr. J. Anim. Sci. 36:135-141.

El-Deek, A. A. and M. A. Brikaa. 2009. Nutritional and biological evaluation of marine seaweed as a feedstuff and as a pellet binder in poultry diet. Int. J. Poult. Sci. 8:875-881.
El-Husseiny, O. M., A. G. Abdallah, and K. O. Abdel-Latif. 2008. The influence of biological feed additives on broiler performance. Int. J. Poult. Sci 7:862-871.

Engberg, R. M., M. S. Hedemann, T. D. Leser, and B. B. Jensen. 2000. Effect of zinc bacitracin and salinomycin on intestinal microflora and performance of broilers. Poult. Sci. 79:13111319.

Jiménez-Escrig, A. and F. J. Sánchez-Muniz. 2000. Dietary fibre from edible seaweeds: Chemical structure, physicochemical properties and effects on cholesterol metabolism. Nutr. Res. 20:585-598.

Jimenez-Escrig, A., E. Gomez-Ordonez, and P. Ruperez. 2011. Seaweed as a source of novel nutraceuticals: Sulfated polysaccharides and peptides. Adv. Food Nutr. Res. 64:325337.

Kang, K. S., I. D. Kim, R. H. Kwon, and B. J. Ha. 2008. Undaria pinnatifida fucoidan extract protects against $\mathrm{CCl} 4$-induced oxidative stress. Biotechnol. Bioprocess Eng. 13:168-173.

Katayama, M., M. Katayama, T. Fukuda, T. Okamura, E. Suzuki, K. Tamura, Y. Shimizu, Y. Suda, and K. Suzuki. 2011. Effect of dietary addition of seaweed and licorice on the immune performance of pigs. Anim. Sci. J. 82:274-281.

Kim, M. H. and H. G. Joo. 2008. Immunomodulatory effects of fucoidan on bone marrow-derived dendritic cells. Immunol. Lett. 115:138-143.

Liu, F., J. Wang, A. K. Changb, B. Liu, L. Yang, Q. Li, P. Wang, and X. Zou. 2012. Fucoidan extract derived from Undaria pinnatifida inhibits angiogenesis by human umbilical vein endothelial cells. Phytomedicine 19:797-803.

Lokaewmanee, K., K. Yamauchi, and N. Thongwittaya. 2012. Effects of fermented plant product on growth performance, some blood variables, carcase characteristics, and intestinal histology in broilers. Br. Poult. Sci. 53:215-223.

MacArtain, P., C. I. Gill, M. Brooks, R. Campbell, and I. R. Rowland. 2007. Nutritional value of edible seaweeds. Nutr. Rev. 65:535-543.

Michel, C., M. Lahaye, C. Bonnet, S. Mabeau, and J. L. Barry. 1996. In vitro fermentation by human faecal bacteria of total and purified dietary fibres from brown seaweeds. Br. J. Nutr. 75:263-280.

Midilli, M., F. Okan, and C. Kemal. 2008. Effects of dietary probiotic and prebiotic supplementation on growth performance and serum IgG concentration of broilers. S. Afr. J. Anim. Sci. 38:21-27.

National Research Council. 1994. Nutrient Requirements of Poultry. 9th Rev. Ed., National Academy Press, Washington, DC, USA.

Phillips, I., M. Casewell, T. Cox, B. D. Groot, C. Friis, R. Jones, C. Nightingale, R. Preston, and J. Waddell. 2004. Does the use of antibiotics in food animals pose a risk to human health? A critical review of published data. J. Antimicrob. Chemother. 53:28-52.

SAS. 2011. User's Guide: Statistics, Version 9.3. Edition. SAS. Inst. Inc., Cary, NC, USA.

Shimada, T., C. Motonaga, S. Matsuura, M. Takagaki, T. Ashida, T. Okano, and H. Morii. 2004. Effects of a fermented vegetable product on fat deposition and bone metabolism in ovariectomized rats. J. Nutr. Sci. Vitaminol. 50:422-425.

Sneath, P. H. A., N. S. Mair, M. E. Sharpe, and J. G. Holt. 1986. 
Bergey's Manual of Systematic Bacteriology. Volume 2. Yuan, Y. V. and N. A. Walsh. 2006. Antioxidant and Williams and Wilkins, Philadelphia.

Ventura, M. R., J. I. R. Castanon, and J. M. McNab. 1994. Nutritional value of seaweed (Ulva rigida) for poultry. Anim. Feed Sci. Technol. 49:87-92.

Wijesinghe, W. and Y. J. Jeon. 2012. Biological activities and potential industrial applications of fucose rich sulfated polysaccharides and fucoidans isolated from brown seaweeds: A review. Carbohydr. Polym. 88:13-20. antiproliferative activities of extracts from a variety of edible seaweeds. Food Chem. Toxicol. 44:1144-1150.

Zhang, J., C. Tiller, J. Shen, C. Wang, G. S. Girouard, D. Dennis, C. J. Barrow, M. Miao, and H. S. Ewart. 2007. Antidiabetic properties of polysaccharide- and polyphenolic-enriched fractions from the brown seaweed Ascophyllum nodosum. Can. J. Physiol. Pharmacol. 85:1116-1123. 